\title{
Effect of Squeeze-out and Sizing Ratio to The Residual Circumferential Stress of HFW Pipe
}

\author{
Siens Harianto ${ }^{1, *}$, Elang Susilaputra ${ }^{2}$, Peter $^{\text {Darto }}{ }^{3}$, and Ardian Fandika ${ }^{4}$ \\ ${ }^{1}$ PT. Indal Steel Pipe, Engineering Department, Maspion Industrial Estate V, Manyar, Gresik, 61151, INDONESIA \\ ${ }^{2}$ PT. Indal Steel Pipe, Production Department, Maspion Industrial Estate V, Manyar, Gresik, 61151, INDONESIA \\ ${ }^{3}$ PT. Indal Steel Pipe, Production Department, Maspion Industrial Estate V, Manyar, Gresik, 61151, INDONESIA \\ ${ }^{4}$ PT. Pertamina Hulu Mahakam, Referential \& Performance Evaluation Division, Jl. Yos Sudarso, Balikpapan, 76123, INDONESIA
}

\begin{abstract}
Residual circumferential stress originates from pipe forming process has a negative impact on the pressure carrying capacity; therefore it is necessary to keep the level of residual stress as low as possible and distributed uniformly around the pipe. Manufacturing of HFW (High-Frequency Welded) pipe involves pinching, bending, forming, welding, squeezing, sizing and straightening processes in several stages which produce both elastic and plastic deformation. Those processes produce residual stresses in the pipe wall in the circumferential and longitudinal directions. This paper presents the result of the trial test to investigate the effect of squeeze-out (SO) and the sizing ratio (SR) to the residual circumferential stress on HFW pipe. The trial was performed at PT INDAL STEEL PIPE (ISP) pipe mill, on pipe API 5L L360MO PSL2, nominal Outside Diameter (OD) $273 \mathrm{~mm}$, wall thickness $12.7 \mathrm{~mm}$. The SO was $0.7 \mathrm{t}$ and $0.9 \mathrm{t}$, while the SR was set at $0.5 \%, 0.8 \%$, and $1.0 \%$.
\end{abstract}

\section{Introduction}

Masubuchi [1] defined residual stress as the stresses that would exist in the material if all external loads were removed. Based on the mechanism, residual stresses are classified in two; those produced by structural mismatching and those produced by the uneven distribution of non-elastic strains, including plastic strains and thermal strains.

Many researchers have studied residual stresses in HFW pipe. Mjaku and Shala [2] reported the measurement of residual stress and strain in HFW pipe using slitting technique and measured the residual stresses using strain gauges. Anderson and Brown [3] investigated the effect of residual stresses due to forming process to the fracture characteristic of ERW pipe using finite element simulation. They reported that the residual stresses due to forming have a significant effect on the integrity of the pipeline when three conditions are met:

1. The seam weld toughness is low.

2. There is surface breaking crack (s) on the OD of the pipe.

3. No cold expansion nor normalizing process during pipe manufacturing

In pipeline application, the code such as ASME B31.8 [4] gives the design factor which limits the utilization of the pipe circumferential (e.g.) hoop stress. The design factor is intended to anticipate the manufacturing imperfection and to give safety factor for pipe utilization. Most of the manufacturing codes gave the maximum permissible imperfection size based on workmanship acceptance criteria.

During the HFW pipe forming process, flat steel coil is cold bent and formed into a pipe by a series of forming rolls (as illustrated in Figure 1) and then longitudinally welded without filler metal. The effect of the cold forming process is developing residual stress in the pipe wall thickness. The residual stress is due to the transversal contraction and compression, and the magnitude depends on the dimension of the pipe (i.e., diameter and wall thickness). The applied strain is a combination of elastic strain and plastic strain. The plastic strain is permanent and will cause strain hardening which alters the pipe mechanical properties (i.e., change of mechanical properties from a coil to pipe), while the elastic strain will remain and cause spring-back effect whenever the pipe is longitudinally cut. This spring-back effect (or so-called residual circumferential stress) together with internal pressure will increase the driving force for the enlargement of imperfection particularly for those with an orientation perpendicular to the pipe hoop stress (e.g., imperfections on longitudinal seam weld).

Distribution of residual circumferential stress also has an important role. If circumferential stress is concentrated in a specific area, then this area can be the critical one. Unlike the Submerged Arc Welded Longitudinal pipe with UOE (U-forming, O-forming, and followed by cold Expansion) or JCOE (J-forming, $\mathrm{C}$-forming, O-forming and followed by cold Expansion) forming process, HFW does not have the cold expansion 
process. The cold expansion is known to have a positive effect to minimize and re-distribute the residual stress. Instead of cold expansion, HFW has compression during welding and followed by sizing after seam heat treatment (see Figure 2). Compression during welding is indicated by squeeze out (SO), and pipe sizing is indicated by sizing ratio $(\mathrm{SR})$.

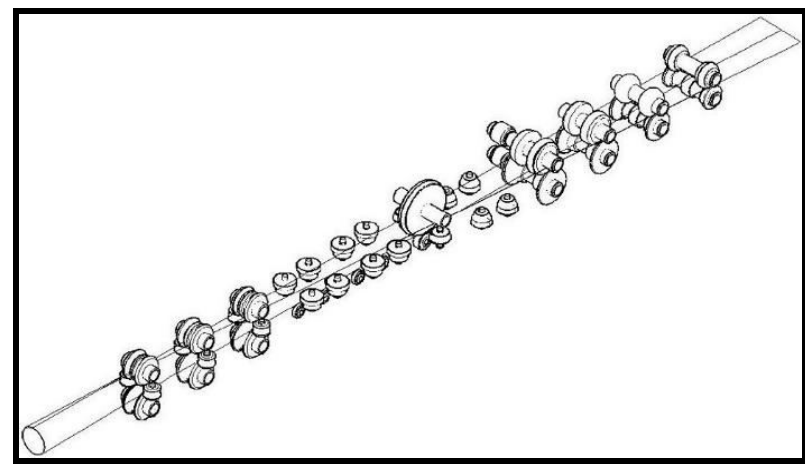

Fig. 1. Forming sequences

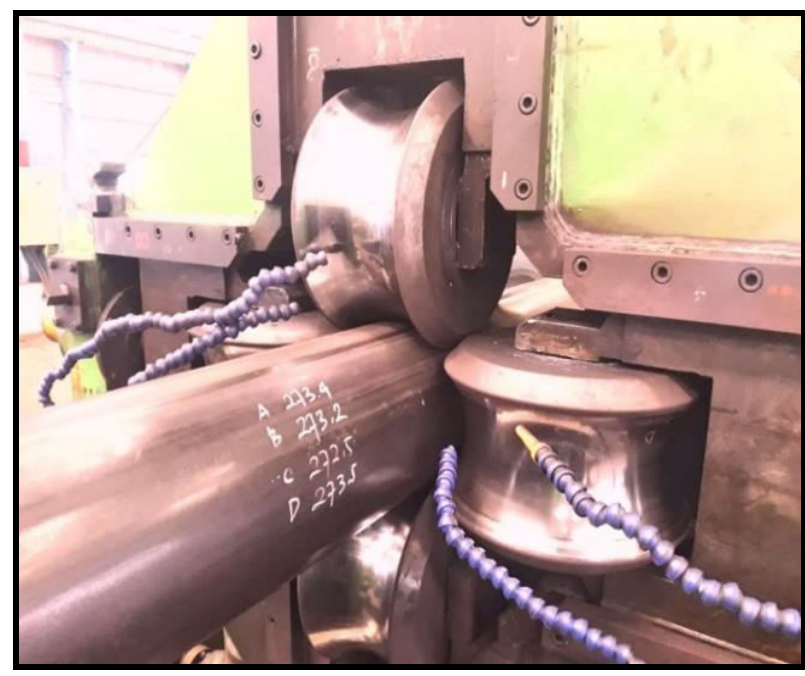

Fig. 2. Sizing roll assembly

The objective of this study is to investigate the effect of SO and SR to the residual circumferential stress through a production experiment performed at ISP pipe mill and this paper present the tests result.

\section{The approach}

During the bending process of a flat product, the outer surface will receive tension stress, and the inner surface will receive compression stress. Figure 3 [5] shows schematic of residual stress in rings. To measure the maximum stress level at OD and inside diameter (ID) pipe is not easy and needs a specific tool while during the pipe manufacturing process, it is necessary to have a quick measurement technique to check the global overview of the state of residual circumferential stress.

Toten et al. [5] and ASTM E1928 [6] gave a practical approach to estimate the global residual circumferential stress based on the net opening of the test ring after being cut or slit in the longitudinal direction. Figure 4 [5] shows schematic of residual stress after slitting. The circumferential stress can be calculated with the below formula:

$$
\sigma_{h}=\left[\frac{E \cdot t}{1-v^{2}}\right]\left[\frac{1}{D_{i}}-\frac{1}{\left(\frac{x}{\pi}+D_{i}\right)}\right]
$$

Where

$$
\begin{aligned}
& \mathrm{E}=\text { modulus of elasticity }(200000 \mathrm{MPa}) \\
& t=\text { thickness of test ring }(\mathrm{mm}) \\
& v=\text { poison's ratio }(0.3) \\
& D_{i}=\text { initial OD of test ring }(\mathrm{mm}) \\
& x=\text { net opening }(\mathrm{mm})
\end{aligned}
$$

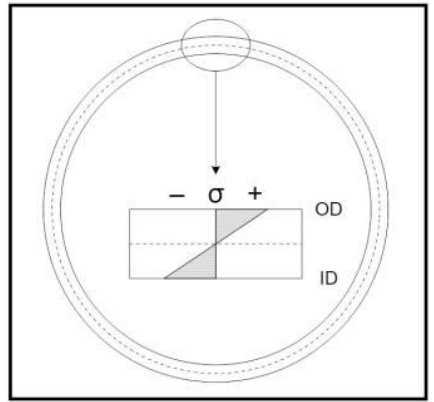

Fig. 3. Schematic of the residual stress distribution in test ring prior slitting.

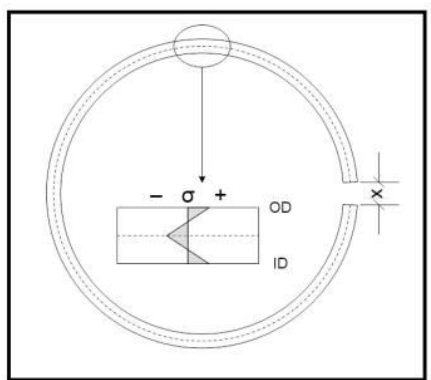

Fig. 4. Schematic of the residual stress distribution in test ring after slitting.

\section{The experiment procedure}

High-frequency welding was carried out on the production of line pipe with $273.1 \mathrm{~mm}$ nominal OD, 12.7 mm wall thickness, steel grade API 5L L360MO PSL2. Coil with nominal thickness $12.7 \mathrm{~mm}(1 / 2 \mathrm{in}$.) and width $832 \mathrm{~mm}$ (after edge milling) is used, while variations on SO and SR were made by changing the set-up on the roll. The SO was set at $0.7 t$ and $0.9 t$; while the SR was set at $0.5 \%, 0.8 \%$, and $1.0 \%$. The SO and SR is defined as follow:

$$
S O=\frac{C_{b w}-C_{a w}}{t}
$$

Where:

$$
\begin{aligned}
& S O=\text { squeeze-out } \\
& C_{b w}=\text { circumferential length prior welding }(\mathrm{mm}) \\
& \mathrm{C}_{\mathrm{aw}}=\text { circumferential length after welding }(\mathrm{mm}) \\
& t \quad=\text { thickness }(\mathrm{mm})
\end{aligned}
$$

$$
S R=\frac{\left|O D_{a}-O D_{b}\right|}{O D_{b}} \times 100
$$

Where:

$$
S R=\text { sizing ratio }(\%)
$$




$$
\begin{aligned}
& O D_{a}=\text { Pipe OD after sizing }(\mathrm{mm}) \\
& O D b=\text { Pipe OD before sizing }(\mathrm{mm})
\end{aligned}
$$

For each testing set-up, there are three test rings in which each test ring will be slit at $0^{\circ}$ (center weld), $90^{\circ}$ and $180^{\circ}$ (see Figure 5 below). The result of the test is presented in Table 1 and Table 2 below.

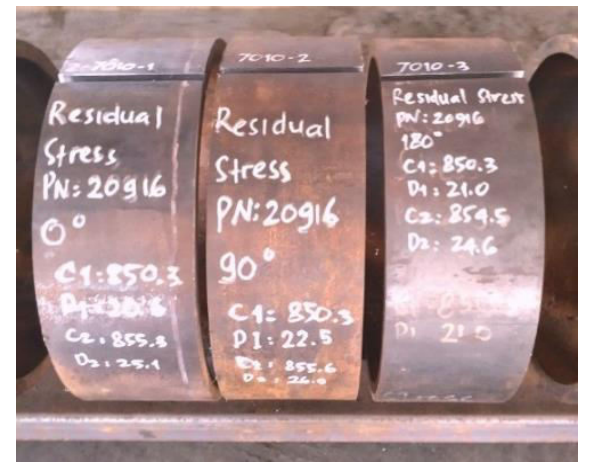

Fig. 5. Test rings for residual circumferential stress.

Table 1. Data from the trial test for SO $0.7 t$

\begin{tabular}{|c|c|c|c|c|c|c|c|c|c|}
\hline SO $(t)$ & \multicolumn{9}{|c|}{0.70} \\
\hline SR (\%) & \multicolumn{3}{|c|}{0.50} & \multicolumn{3}{c|}{0.80} & \multicolumn{3}{c|}{1.00} \\
\hline Slit location & $0^{\circ}$ & $90^{\circ}$ & $180^{\circ}$ & $0^{\circ}$ & $90^{\circ}$ & $180^{\circ}$ & $0^{\circ}$ & $90^{\circ}$ & $180^{\circ}$ \\
\hline Net opening (mm) & 6.6 & 6.3 & 5.5 & 4.6 & 5.1 & 3.7 & 4.5 & 4.4 & 3.6 \\
\hline $\begin{array}{c}\text { Residual stress } \\
\text { (MPa) } \\
\text { / of SMYS }\end{array}$ & 78.62 & 75.07 & 65.60 & 55.26 & 61.23 & 44.49 & 54.29 & 53.09 & 43.48 \\
\cline { 2 - 10 } |Max - Min| (MPa) & 22.30 & 21.30 & 18.61 & 15.67 & 17.37 & 12.62 & 15.40 & 15.06 & 12.33 \\
\hline Ma.02 & \multicolumn{3}{c|}{16.74} & \multicolumn{3}{c|}{10.81} \\
\hline
\end{tabular}

Table 2. Data from the trial test for SO $0.9 t$

\begin{tabular}{|c|c|c|c|c|c|c|c|c|c|}
\hline SO $(t)$ & \multicolumn{9}{|c|}{0.90} \\
\hline SR (\%) & \multicolumn{3}{|c|}{0.50} & \multicolumn{3}{c|}{0.80} & \multicolumn{3}{c|}{1.00} \\
\hline Slit location & $0^{\circ}$ & $90^{\circ}$ & $180^{\circ}$ & $0^{\circ}$ & $90^{\circ}$ & $180^{\circ}$ & $0^{\circ}$ & $90^{\circ}$ & $180^{\circ}$ \\
\hline Net opening (mm) & 5.4 & 5.1 & 4.8 & 4.7 & 4.1 & 3.7 & 5.2 & 4.5 & 4.5 \\
\hline $\begin{array}{c}\text { Residual stress } \\
\text { (MPa) }\end{array}$ & 64.79 & 61.21 & 57.63 & 56.78 & 49.57 & 44.75 & 63.04 & 54.60 & 54.60 \\
\cline { 2 - 10 } / of SMYS & 18.38 & 17.36 & 16.35 & 16.11 & 14.06 & 12.70 & 17.88 & 15.49 & 15.49 \\
\hline |Max - Min| (MPa) & \multicolumn{3}{|c|}{7.16} & \multicolumn{3}{c|}{12.03} & \multicolumn{3}{c|}{8.44} \\
\hline
\end{tabular}

\section{Discussion}

The selection of squeeze out is based on the pragmatic approach where the target for metal flow angle at $1 / 4 t$ and $3 / 4 t$ should be in between $50^{\circ}$ and $80^{\circ}$.

Apparently at both SO set-ups, the metal flow angle can satisfy this requirement (see Figure 6 and Figure 7 below).

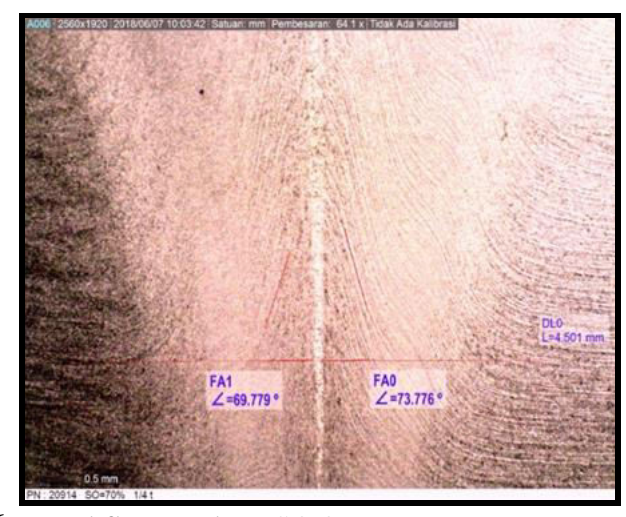

Fig. 6. Metal flow angle at SO $0.7 t$.

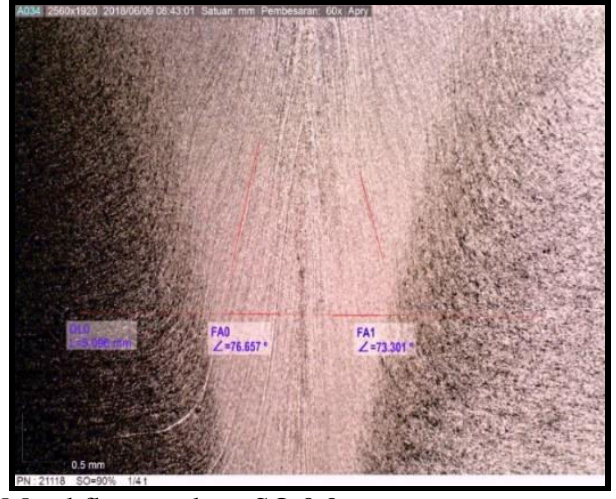

Fig. 7. Metal flow angle at SO 0.9t.

The SO has less effect on residual circumferential stress because the compression force is concentrated on the weld area; however, it is necessary to ensure the metal flow angle within the range of $50^{\circ}-80^{\circ}$ in order to ensure that all the oxides have been expelled from abutting surfaces.

The SR has a more significant effect to reduce and to redistribute the residual circumferential stress (see Figure 8 and Table 2 below). This mainly due to the compressive stress is distributed along the pipe circumferential and less soft spot due to lower pipe temperature.

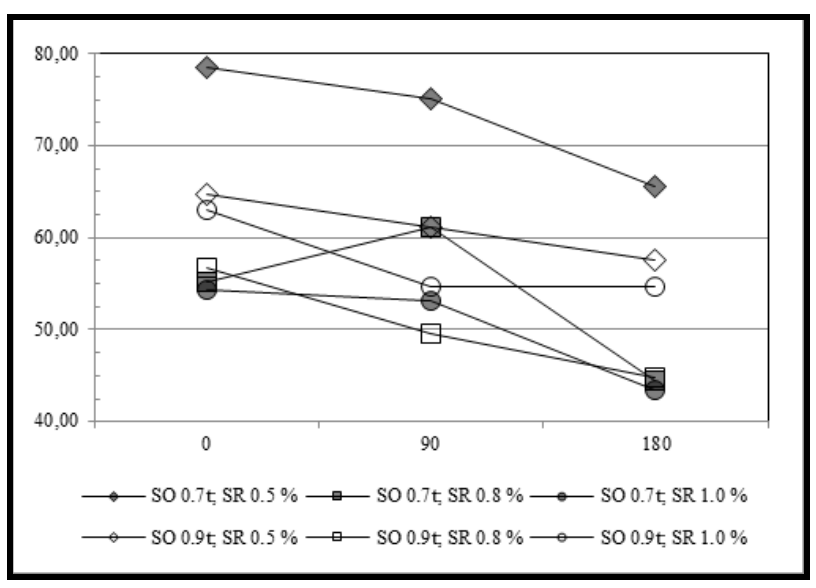

Fig. 8. Comparison chart from test results

\section{Conclusion}

From the results of this study, it is concluded that SO and SR have a positive impact on the residual circumferential stress of HFW pipe.

At both SO $0.7 t$ and $0.9 t$, metal flow angle at $1 / 4 t$ and $3 / 4 t$ can be maintained in between $65^{\circ}$ and $80^{\circ}$ in which it can be assured that all oxides can be expelled from the welded surface.

The effect of SO to the distribution and level of residual circumferential stress is small because the compressive stress is concentrated at the welded area. The higher the SO, the greater metal flow angle will be.

The effect of SR to the distribution and level of residual circumferential stress is higher because the pipe has a lower temperature (e.g., less soft spot) and thus compressive stress can be distributed along the pipe 
circumferential. The higher the SR, the lower and the more uniform residual circumferential stress will be.

This study certainly will help the pipe mill to have a better understanding of the HFW manufacturing process and to satisfy purchaser's particular specification [7].

\section{Future works}

As a continuation of this study, further research of the change of mechanical properties from a coil to pipe due to the change of the SO and SR need to be carried out.

Furthermore, it is necessary to repeat the ring split residual stress test on the aged sample and to measure the change of residual circumferential stress.

The authors would like to thank the management of PT. Indal Steel Pipe for generous support and contribution of the experimental works.

\section{References}

1. K. Masubuchi, Analysis of Welded Structures (Pergamon Press, Oxford, 1980)

2. M. Mjaku, A. Shala, Int. J. of Eng., XVI, 47-51 (2018)

3. T.L. Anderson, G.W. Brown, Proceeding of $11^{\text {th }}$ International Pipeline Conference, Calgary, Alberta, Canada, September 26-30 (2016)

4. ASME B31.8 (2016)

5. G. Totten, M. Howes, T. Inoue, Handbook of residual stress and deformation of steel - deflection methods to estimate residual stress, 89-98 (2002)

6. ASTM E1928 (2013)

7. Pertamina Hulu Mahakam, MHK-COMP-SPERPE-MAT 0101 Specification for carbon steel line pipe, (2018) 